\title{
CASE SHOWN AT THE M.R.C.P. COURSE.
}

Henry K. aet. 39 years, was first seen as a case of purpura. The history he gave was that he had been perfectly well until two months ago, when he contracted a sore throat followed by a cough. The sore throat subsided after three weeks, but was almost immediately followed by a second sore throat. A month ago he developed "boils" on his face, neck and left arm. For the past six to seven weeks he had noticed increasing pallor, and complained chiefly of extreme lethargy and drowsiness.

On examination, he was very pale, and obviously anæmic. He showed purpuric spots on the front and back of his legs and trunk, and to a less extent on the arms, face, and neck. The "boils" were hæmorrhagic areas with small necrotic centres. His gums were bleeding spontaneously, and he complained of considerable "toothache" from the tenderness round some of the teeth. No glands could be palpated but a soft enlargement of the spleen could be felt below the costal margin.

The case was discussed mainly from the point of view of the causes of severe purpura. The classification adopted, which will include most of the types met with, was $(a)$ infective purpura associated with the hæmorrhagic form of severe measles, scarlet fever, or with small-pox, typhus, spirochætosis ictero-hæmorrhagica or malaria. Under this heading septicæmia and malignant endocarditis were included. (b) Toxic, as from a focus with a hæmolytic streptococcus; from endogenous toxins in Bright's disease, severe jaundice, gout; and from drugs, especially with salicylates, the antipyretics, arsenic, etc. (c) The chief blood diseases that give purpura were found to be leukæmia, lymphadenoma, pernicious anæmia, aplastic anæmia and primary thrombo-cytopenia. In all these the platelets tended to be low, but the bleeding did not always correspond with the lowest levels. (d) Cachectic conditions, such as advanced tubercle and carcinomatosis; and $(e)$ occasionally some nervous diseases, such as tabes and syringomyelia, were included to complete the list.

In the present case, the diagnosis of acute leukæmia was generally accepted, especially in view of the accompanying anæmia, the palpable spleen and the characteristic drowsiness. This was confirmed by the blood count which showed Hb. 42 per cent.; R.B.C. 2,I00,000; C.I. I.o; W.B.C. 8,I00 (polymorphs 9.0\%, lymphocytes II.5\%, myelocytes I9.0\%, and myeloblasts $60.5 \%$ ). Blood platelets, I6,000. The other points brought out by discussion were the severe and rapidly fatal forms usually manifested by a case showing such a high percentage of myeloblasts, and the much greater tendency to secondary infections exhibited when the total number of polymorphs was so low as in the present case. 